\title{
The utilization of copper/zeolite as catalyst in the microwave-assisted synthesis of some novel sulfonamide derivatives
}

\author{
Selvakumar DINESHKUMAR, Ganesamoorthi THIRUNARAYANAN*, \\ Perumal MAYAVEL, and Inbasekaran MUTHUVEL
}

Department of Chemistry, Annamalai University, Annamaliangar-608002, Tamilnadu, India

\begin{abstract}
Zeolite Y clay modified copper nitrate catalyst was prepared. The obtained catalyst was analyzed by SEM, EDS, and powder XRD techniques. The zeolite Y clay modified copper nitrate catalyst was used for the synthesis of various substituted mesalazine by sulfonylation. The synthesized sulfonamides have been characterized by GC-MS, IR, ${ }^{1} \mathrm{H},{ }^{13} \mathrm{C}$ and HSQC NMR techniques. The yield percentages of sulfonamides are more than $85 \%$.
\end{abstract}

Keywords: sulfonamides, copper-zeolites, FT-IR, NMR spectra, GC-mass, SEM, EDS, powder XRD.

\section{Introduction}

In recent years the microwave techniques play an important role with more attention to the organic chemists. Because the solvent free microwave method has more selectivity, easiest separation, higher yield, eases of isolation of product, less energy consumption than the conventional solvent methods, this method is used in industries to avoid large volume consumption of solvents [1]. In order to protect mesalazine (5-aminosalicylic acid) compound, sulfonyl chloride based nitrogen protecting method is easy to carryout. In general sulfonamides possess $-\mathrm{SO}_{2}-\mathrm{NH}$ - moiety in their structures. Sulfonamides have been obtained by condensation between primary or secondary amine with sulfonyl chloride. Zeolites are generally known to be an alumina silicate composition. Due to its high porous structure, shape selectivity, good thermal stability, ease of handling, non-corrosiveness, reusability and low cost, zeolites show more interest between researchers, being widely used as absorbents and also catalysts. They have considerable advantages, such as ordered and use of nonpolluting natural minerals [2]. Therefore these catalysts avoid the long reaction time, unsatisfactory yield, expensive and hazardous nature. In the past years many solid supported reusable catalysts are employed for the preparation of sulfonamides, such as $\mathrm{CuO}$ ([2]), montmorillonite $-\mathrm{KSF}$, montmorillonite $-\mathrm{K} 10$, $\mathrm{CsF}$ - Celite [3-6], metal carbonates $\left(\mathrm{Na}_{2} \mathrm{CO}_{3}, \mathrm{~K}_{2} \mathrm{CO}_{3}\right)$ [7], metal oxides ( $\mathrm{CdO}$ [8], and acid acceptor's such as pyridine [9], triethylamine [10], $\mathrm{NaOH}$ has also been used in the earlier reported reaction. In order to avoid the side reaction in formation of bis-tosylated byproducts, industrial researchers are searching a new toolkit for a selectivity based reactions. Within the above view there is no report available in literature for the use of the $\mathrm{Cu}^{2+} /$ zeolite catalyst in the microwave-assisted synthesis of sulfonamides. Therefore, the authors have taken efforts to prepare the $\mathrm{Cu}^{2+} /$ zeolite catalyst and used it for synthesis of sulfonamides.

\section{Experimental}

\subsection{Materials and methods}

All the chemicals used in this investigation were purchased from the Sigma-Aldrich, Alfa Aesar and E. Merck chemical companies. Melting points of all sulfonamides have been determined in open glass capillaries on Mettler FP51 melting point apparatus and are uncorrected. Infrared spectra $(\mathrm{KBr}, 4000$ $400 \mathrm{~cm}^{-1}$ ) were recorded on OMNIC Fouriertransform spectrophotometer. Bruker AV400 \& 500 NMR spectrometer operating at $400 \mathrm{MHz} \& 500$ $\mathrm{MHz}$ was used to record ${ }^{1} \mathrm{H},{ }^{13} \mathrm{C}$ and HSQC (Heteronuclear Single Quantum Coherence Spectroscopy) NMR spectra in DMSO solvent, using TMS as internal standard. Mass spectra were recorded on a Simadzu GC-MS2010 spectrometer using Chemical Impact (CI) techniques. The SEM images of the catalysts were recorded on the Ametex SEM instrument. The Bruker AXS D8 Advance Xray diffractometer was used to record powder XRD pattern of catalyst. The $\mathrm{CHN}$ elemental analysis of all sulfonamides was performed in Thermo Finnigan analyzer.

\subsection{Preparation and characterization of $\mathrm{Cu}^{2+} /$ zeolite clay catalyst}

About $50 \mathrm{~mL}$ of $0.05 \mathrm{M} \mathrm{Cu}\left(\mathrm{NO}_{3}\right)_{2}$ in isopropanol solution was added to zeolite clay suspension drop

\footnotetext{
* Corresponding author: drgtnarayanan@gmail.com
} 
wise using separating funnel, with constant stirring, using a magnetic stirrer. Zeolite suspension was prepared by about $1 \mathrm{gm}$ of zeolite clay was dispersed in $50 \mathrm{~mL}$ of isopropanol in a $250 \mathrm{~mL}$ beaker. After complete the transformation of $\mathrm{Cu}\left(\mathrm{NO}_{3}\right)_{2}$ solution to the zeolite suspension, the mixture was sonicated to get a fine power. The resulting solution was stirred for $4 \mathrm{~h}$ at room temperature. The solution was slowly evaporated at room temperature. The obtained solid was dried at $110^{\circ} \mathrm{C}$ for $5 \mathrm{~h}$ and grind with a pestle and mortar affords the $\mathrm{Cu}^{2+}$ /zeolite clay catalyst as fine powder. This catalyst was calcined at $250^{\circ} \mathrm{C}$. The obtained $\mathrm{Cu}^{2+} /$ zeolite catalyst was characterized by the powder XRD (X-Ray Diffraction), SEM (Scanning Electron Microscopy), and EDS (Energy Dispersive X-ray Spectroscopy) analysis.

\subsection{Experimental procedure for the sulfonylation of mesalazine}

An equimolar concentration of substituted sulfonyl chlorides (1 mmol), mesalazine $(1 \mathrm{mmol})$ and $\mathrm{Cu}^{2+} /$ zeolite $(80 \mathrm{mg}$ ) clay catalyst were taken in $100 \mathrm{~mL}$ beaker and mixed thoroughly. This mixture was subjected to microwave irradiation for 5-8 minutes in a microwave oven (Scheme 1) at $450 \mathrm{~W}$ (Samsung Grill, GW73BD Microwave oven, 230V $\mathrm{A} / \mathrm{c}, 50 \mathrm{~Hz}, 2450 \mathrm{~Hz}, 100-750 \mathrm{~W}$ (IEC-705)). During the reaction $0.1 \mathrm{~mL}$ of triethylamine was added to neutralize the formation of hydrochloride. The completion of the reaction was monitored by thin layer chromatography. The resulting product was washed with $n$-hexane and separated the catalyst using methanol by filtration, and dried. The catalyst was reused for further reaction runs.

\section{Results and Discussion}

\subsection{SEM analysis of $\mathrm{Cu}^{2+} /$ zeolite catalyst}

The SEM analysis reveals the surface morphology and range of size of loaded ions present in the catalyst. Zeolite and $\mathrm{Cu}^{2+}$ /zeolite catalyst surface morphology were shown in Fig. 1 (a, b). In Fig. 1.a, the SEM image shows the cubical shape with the clear surface, which is typical structure for zeolite. Fig. 1.b reveals the modification of zeolite surface by copper, the $\mathrm{Cu}^{2+}$ ions being spread over on the zeolite surface, as it was confirmed by EDS spectrum (Fig. 1.d) coupled with SEM.

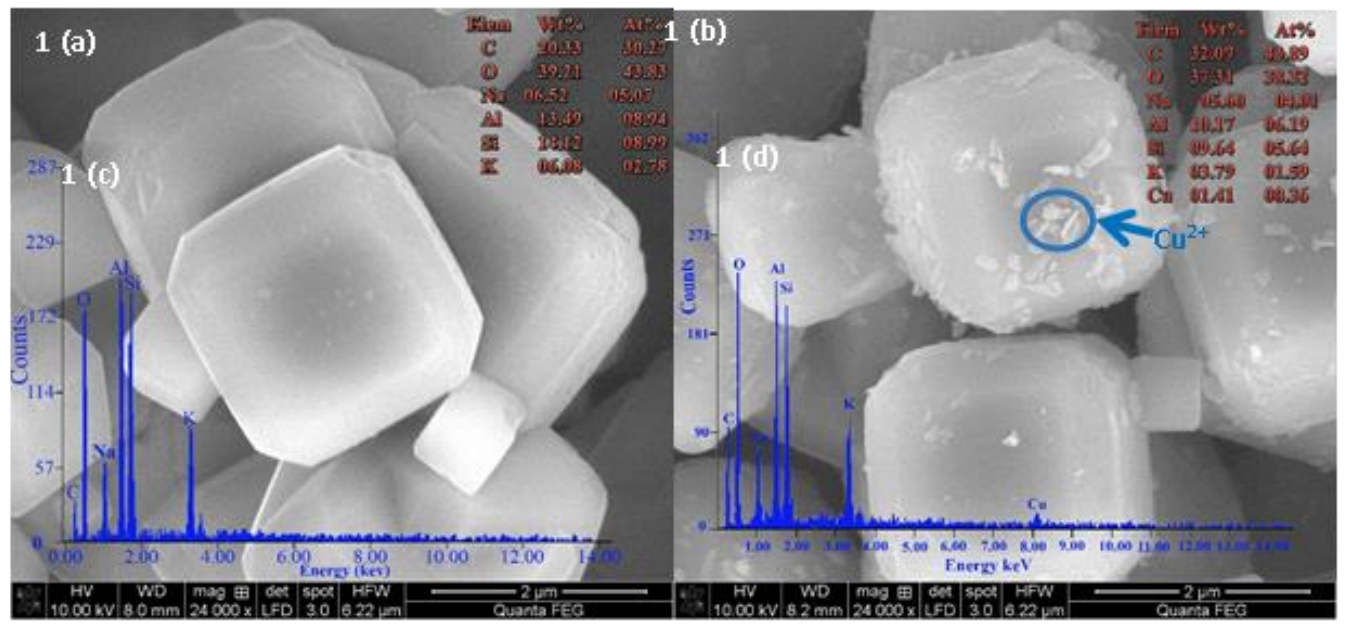

Figure 1. SEM image of (a) zeolite (b) copper on zeolite catalyst; EDS spectra of (c) zeolite (d) copper on zeolite catalyst

The surface morphology on the cubical shape indicates $\mathrm{Cu}^{2+}$ particles perfectly located on zeolite matrix. The modifications of surface by copper ions are indicated by circle. The chemical composition of zeolite and copper loaded zeolite catalyst were examined by EDS analysis and it is shown in Fig. 1(cd). In Fig. 1.c, the EDS spectrum reveals that the major components such as $\mathrm{SiO}_{2}, \mathrm{Al}_{2} \mathrm{O}_{3}$ were present, in addition with $\mathrm{Na}, \mathrm{K}$ elements, also observed in zeolite. In the Fig. 1.d, the EDS spectrum shown that the $\mathrm{Cu}^{2+} /$ zeolite catalyst have the chemical composition of $\mathrm{Cu}, \mathrm{SiO}_{2}$, and $\mathrm{Al}_{2} \mathrm{O}_{3}$. The results show that the $\mathrm{Cu}^{2+}$ ions are successfully loaded on the zeolite matrix.

\subsection{Powder $X$-ray diffraction analysis of $\mathrm{Cu}^{2+} /$ zeolite catalyst}

The crystalline phase of zeolite and copper loaded zeolite were examined by powder X-ray diffraction (XRD) patterns and are shown in Fig. 2.a and b. The zeolite is a mixture of silica and alumina oxides. Fig. 2.b shows the powder XRD pattern of copper loaded zeolite. The diffraction of $\mathrm{Cu}^{2+}$ loaded zeolite patterns are appeared at $10.35^{\circ}, 21.54^{\circ}, 26.31^{\circ}, 34.19^{\circ}$, $53.35^{\circ}$, and $69.66^{\circ}$. The corresponding diffraction planes are (100), (012), (112), (122), (112), (112), (142) and (602). These diffraction peaks were in good agreement with the corresponding crystallography open database (COD No-96-403-0745) [11]. 


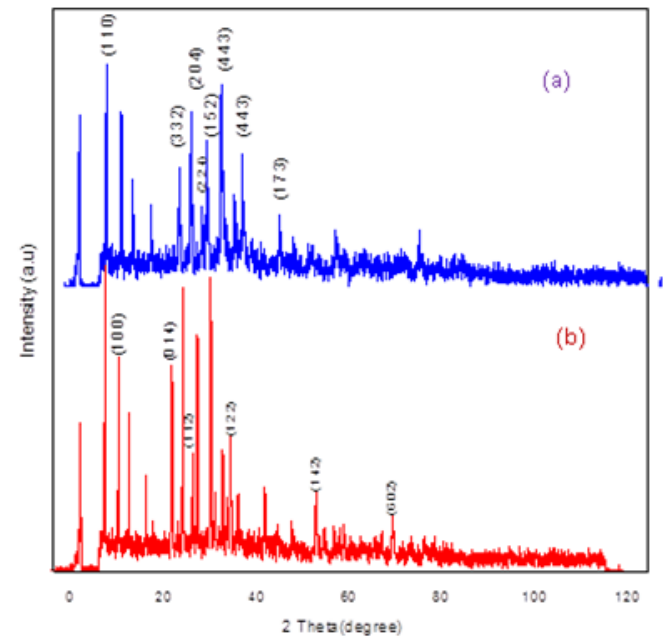

Figure 2. XRD patterns of (a) zeolite $Y($ b) copper loaded zeolite catalyst.

\subsection{Effect of catalyst loading}

In the present investigation, the authors have synthesized various substituted mesalazine sulfonamides by microwave method. In this synthesis work the authors have studied the effect of catalyst loading by obtained product percentage by the reaction between equimolar quantity of 4chlorosulfonylchloride and mesalazine (Scheme 1, entry 3).

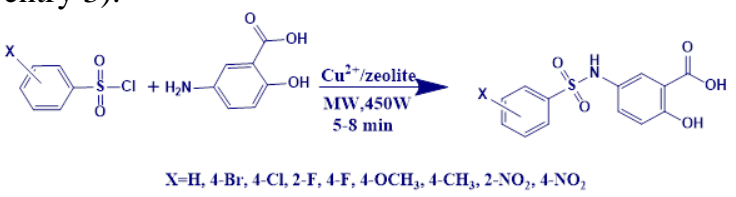

Scheme 1. Synthesis of substituted mesalazines.

The yields about $80 \%$ of product were obtained up to the 20-40 mg of catalyst loading (Fig. 3). The yield was increased from 80 to $90 \%$ by increasing the amount of the catalyst.

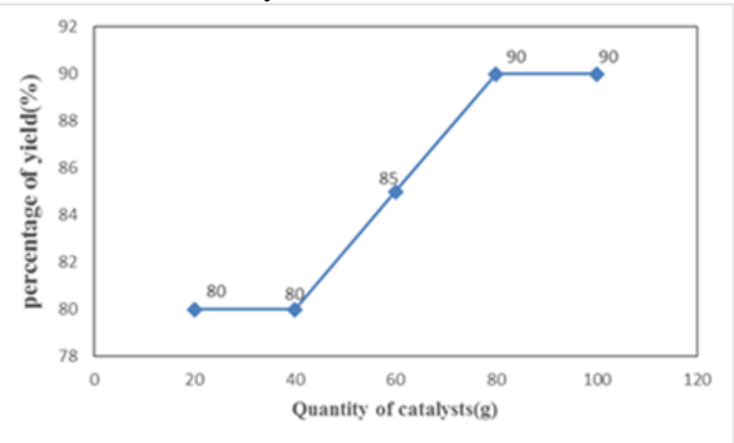

Figure 3. Effect of catalyst loading.

From these observations, the optimum quantity of the catalyst found to be $80 \mathrm{mg}$ for the synthesis of sulfonamides. Beyond $80 \mathrm{mg}$ of catalyst loading, there is no increasing the yield of product.

\subsection{Optimization of catalyst}

Further the authors have investigated the efficiency of this $\mathrm{Cu}^{2+} /$ zeolite catalyst by combines with various metal oxide catalysts such as $\mathrm{ZnO}, \mathrm{NiO}$, $\mathrm{TiO}_{2}, \mathrm{CuO}, \mathrm{Al}_{2} \mathrm{O}_{3}$ and copper on $\mathrm{Al}_{2} \mathrm{O}_{3}, \mathrm{SiO}_{2}$ and copper on $\mathrm{SiO}_{2}$ by microwave irradiation method. The amount of the catalyst and the yield of the reaction were tabulated in Table 1.

Table. 1. Optimization of the reaction conditions.

\begin{tabular}{|c|c|c|c|c|c|}
\hline $\begin{array}{l}\text { En } \\
\text { try }\end{array}$ & Catalyst & $\begin{array}{c}\text { Weight } \\
\text { (mg) }\end{array}$ & Base & $\begin{array}{l}\text { Time } \\
\text { (min) }\end{array}$ & $\begin{array}{c}\text { Yield } \\
(\%)\end{array}$ \\
\hline 1 & $\mathrm{ZnO}$ & 100 & $\mathrm{NEt}_{3}$ & 10 & 50 \\
\hline 2 & $\mathrm{NiO}$ & 100 & $\mathrm{NEt}_{3}$ & 9 & 30 \\
\hline 3 & $\mathrm{TiO}_{2}$ & 100 & $\mathrm{NEt}_{3}$ & 15 & 30 \\
\hline 4 & $\mathrm{CuO}$ & 100 & $\mathrm{NEt}_{3}$ & 5 & 70 \\
\hline 5 & $\mathrm{Al}_{2} \mathrm{O}_{3}$ & 150 & $\mathrm{NEt}_{3}$ & 20 & 70 \\
\hline 6 & $\begin{array}{l}\mathrm{Cu} \text { on } \\
\mathrm{Al}_{2} \mathrm{O}_{3}\end{array}$ & 100 & $\mathrm{NEt}_{3}$ & 10 & 80 \\
\hline 7 & $\mathrm{SiO}_{2}$ & 150 & $\mathrm{NEt}_{3}$ & 20 & 70 \\
\hline 8 & $\begin{array}{c}\mathrm{Cu} \text { on } \\
\mathrm{SiO}_{2}\end{array}$ & 100 & $\mathrm{NEt}_{3}$ & 8 & 80 \\
\hline 9 & Zeolite & 150 & $\mathrm{NEt}_{3}$ & 15 & 60 \\
\hline 10 & $\begin{array}{l}\mathrm{Cu} \text { on } \\
\text { zeolite }\end{array}$ & 80 & $\mathrm{NEt}_{3}$ & 5 & 90 \\
\hline
\end{tabular}

In the optimization study $100 \mathrm{mg}$ of $\mathrm{ZnO}$ catalyst gave $50 \%$ yield with 10 minutes (50\% entry 1$)$. The same amount of $\mathrm{NiO}$ and $\mathrm{TiO}_{2}$ catalysts gave poor yield (30\%, entry 2 and 3). About $150 \mathrm{mg}$ of $\mathrm{CuO}$, $\mathrm{Al}_{2} \mathrm{O}_{3}$, and $\mathrm{SiO}_{2}$ catalysts gave $70 \%$ yields (entry 4,5 and 7). The catalysts $\mathrm{Cu}-\mathrm{Al}_{2} \mathrm{O}_{3}$ and $\mathrm{Cu}-\mathrm{SiO}_{2}$ gave $80 \%$ product (entries 6 and 8 ). Only $60 \%$ of the product was observed in the reaction catalyzed by zeolite catalyst (entry 9). The prepared $80 \mathrm{mg}$ of $\mathrm{Cu}$ on zeolite catalyst gave highest yield $90 \%$ of mesalazine within 5 minutes. Within the observations, the $\mathrm{Cu}$-zeolite catalyst (Table 1, entry 10) have good efficiency for catalyzing the reaction between sulfonyl chloride and mesalazine. The percentage of obtained product with catalysts in the optimized condition was illustrated in Fig. 4.

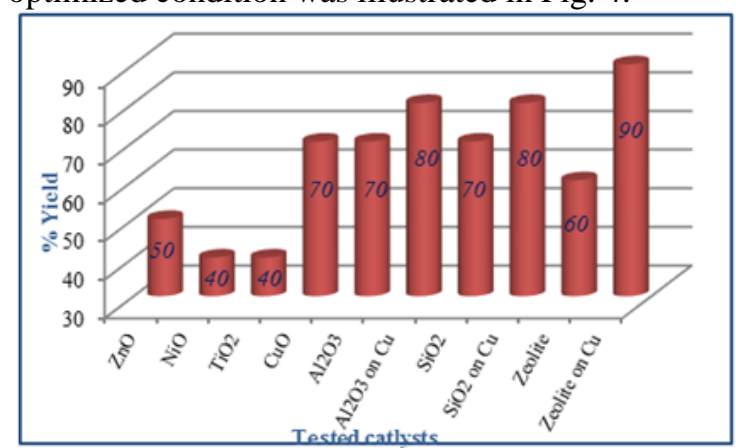

Figure 4. Effect of various catalyst loading on synthesis of 5-(4-chlorophenylsulfonamido)-2hydroxybenzoic acid.

In this reaction, the proposed mechanism was illustrated in Fig. 5. The lone pair electrons of 
nitrogen atom of amine donates the sulfur atom of sulfonyl chloride, the nitrogen gets the charge and leads to quaternary ammonium chloride analogs. Leaves one proton from quaternary ammonium chloride moiety as $\mathrm{HCl}$ by the addition of triethylamine leads to form the sulfonamides.

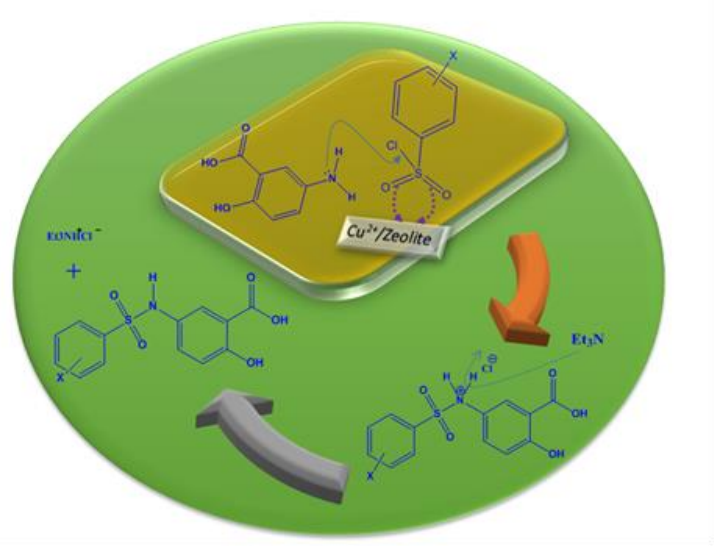

Figure 5. Plausible mechanism of formation of substituted mesalazine sulfonamide derivatives.

\subsection{Stability and reusability of catalyst}

In order to activate the reaction with the recovered catalyst for next run, it was washed with methanol and regenerated by calcined at $110^{\circ} \mathrm{C}$ for subsequent reactions. From Table 2 is shown that the catalytic activity was decreased significantly with the freshly prepared catalysts.

Table 2. Reusability of $\mathrm{Cu}^{2+} /$ zeolite catalyst on synthesis of 5-(4-chlorophenylsulfonamido)-2hydroxybenzoic acid under microwave irradiation (entry 3$)$.

\begin{tabular}{|c|c|c|c|c|c|}
\hline No of runs & 1 & 2 & 3 & 4 & 5 \\
\hline$\%$ of the product & 90 & 88 & 87 & 86 & 86 \\
\hline
\end{tabular}

The correlated diagram of $\%$ of product $v s$ number of runs is shown in Fig. 6.

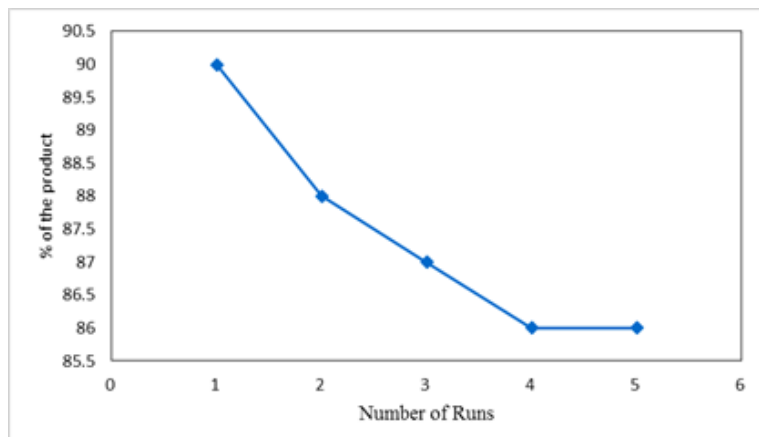

Figure 6. Reusability of catalyst on synthesis of 5(4-chlorophenylsulfonamido)-2-hydroxybenzoic acid.

\subsection{HSQC spectrum}

These data of 5-(4-chlorophenylsulfonamido)-2hydroxybenzoic acid compound (entry 3 , Table 3 and Table 4) was confirmed by HSQC (Fig. 7).

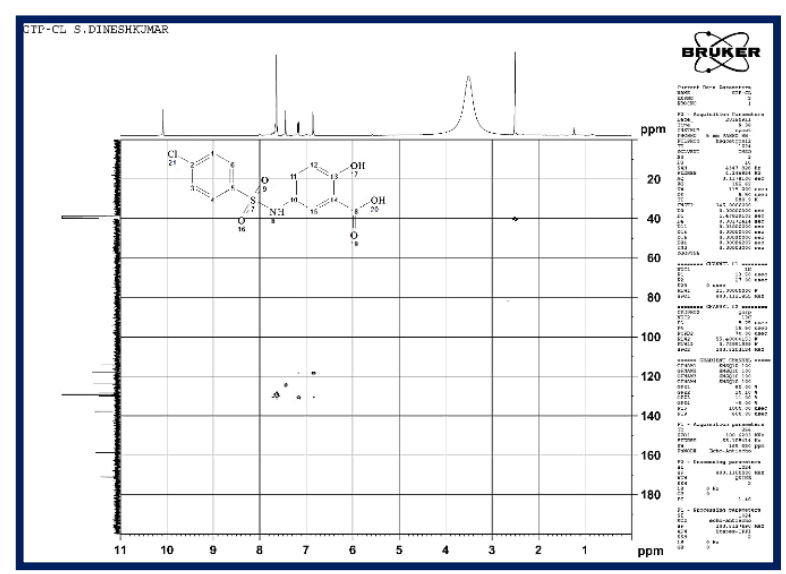

Figure 7. HSQC spectrum of 5-(4chlorophenylsulfonamido)-2-hydroxybenzoic acid.

Table 3. The physical constants, analytical and mass spectral data of mesalazine sulfonamide compounds.

\begin{tabular}{|c|c|c|c|c|c|c|c|c|c|c|}
\hline $\begin{array}{l}\text { En } \\
\text { try }\end{array}$ & $\mathrm{X}$ & M.F & M.W & $\begin{array}{c}\text { Yield } \\
(\%)\end{array}$ & $\begin{array}{l}\text { Time } \\
(\min )\end{array}$ & $\begin{array}{l}\text { M.p } \\
\left({ }^{\circ} \mathrm{C}\right)\end{array}$ & $\begin{array}{c}\mathrm{C}(\%) \\
\text { Obd } \\
\text { (calcd) }\end{array}$ & $\begin{array}{c}\mathrm{H}(\%) \\
\text { Obd } \\
\text { (calcd) }\end{array}$ & $\begin{array}{c}\mathrm{N}(\%) \\
\text { Obd } \\
\text { (calcd) }\end{array}$ & $\begin{array}{l}\text { Mass } \\
(\mathrm{m} / \mathrm{z})\end{array}$ \\
\hline 1 & $\mathrm{H}$ & $\mathrm{C}_{13} \mathrm{H}_{11} \mathrm{NO}_{5} \mathrm{~S}$ & 293.30 & 88 & 5.30 & 276 & $\begin{array}{c}53.26 \\
(53.24)\end{array}$ & $\begin{array}{c}3.76 \\
(3.78)\end{array}$ & $\begin{array}{c}4.72 \\
(4.78)\end{array}$ & $293\left[\mathrm{M}^{+}\right]$ \\
\hline 2 & $4-\mathrm{Br}$ & $\mathrm{C}_{13} \mathrm{H}_{10} \mathrm{BrNO}_{5} \mathrm{~S}$ & 372.19 & 90 & 5 & 305 & $\begin{array}{c}41.99 \\
(41.95)\end{array}$ & $\begin{array}{c}2.69 \\
(2.71)\end{array}$ & $\begin{array}{c}3.71 \\
(3.76)\end{array}$ & $370\left[\mathrm{M}^{+}\right], 372\left[\mathrm{M}^{2+}\right]$ \\
\hline 3 & $4-\mathrm{Cl}$ & $\mathrm{C}_{13} \mathrm{H}_{10} \mathrm{ClNO}_{5} \mathrm{~S}$ & 327.74 & 90 & 5 & 310 & $\begin{array}{c}47.68 \\
(47.64)\end{array}$ & $\begin{array}{c}2.99 \\
(3.08)\end{array}$ & $\begin{array}{c}4.18 \\
(4.27)\end{array}$ & $327\left[\mathrm{M}^{+}\right], 329\left[\mathrm{M}^{2+}\right]$ \\
\hline 4 & $2-\mathrm{F}$ & $\mathrm{C}_{13} \mathrm{H}_{10} \mathrm{FNO}_{5} \mathrm{~S}$ & 311.29 & 86 & 7 & $\begin{array}{l}277- \\
281\end{array}$ & $\begin{array}{c}50.20 \\
(50.16)\end{array}$ & $\begin{array}{c}3.18 \\
(3.24)\end{array}$ & $\begin{array}{c}4.46 \\
(4.50)\end{array}$ & $311\left[\mathrm{M}^{+}\right], 313\left[\mathrm{M}^{2+}\right]$ \\
\hline 5 & $4-\mathrm{F}$ & $\mathrm{C}_{13} \mathrm{H}_{10} \mathrm{FNO}_{5} \mathrm{~S}$ & 311.29 & 88 & 5 & $\begin{array}{l}291- \\
293\end{array}$ & $\begin{array}{c}50.14 \\
(50.16)\end{array}$ & $\begin{array}{c}3.20 \\
(3.24)\end{array}$ & $\begin{array}{c}4.45 \\
(4.50)\end{array}$ & $311\left[\mathrm{M}^{+}\right], 313\left[\mathrm{M}^{2+}\right]$ \\
\hline 6 & $4-\mathrm{OCH}_{3}$ & $\mathrm{C}_{14} \mathrm{H}_{13} \mathrm{NO}_{6} \mathrm{~S}$ & 323.32 & 85 & 8 & 301 & $\begin{array}{c}52.08 \\
(52.01)\end{array}$ & $\begin{array}{c}4.01 \\
(4.05)\end{array}$ & $\begin{array}{c}4.29 \\
(4.33)\end{array}$ & $323\left[\mathrm{M}^{+}\right]$ \\
\hline 7 & $4-\mathrm{CH}_{3}$ & $\mathrm{C}_{14} \mathrm{H}_{13} \mathrm{NO}_{5} \mathrm{~S}$ & 307.32 & 85 & 8 & 282 & $\begin{array}{c}54.68 \\
(54.71)\end{array}$ & $\begin{array}{c}4.22 \\
(4.26)\end{array}$ & $\begin{array}{c}4.49 \\
(4.56)\end{array}$ & $307.05\left[\mathrm{M}^{+}\right]$ \\
\hline 8 & $2-\mathrm{NO}_{2}$ & $\mathrm{C}_{13} \mathrm{H}_{10} \mathrm{~N}_{2} \mathrm{O}_{7} \mathrm{~S}$ & 338.29 & 86 & 7 & 314 & $\begin{array}{c}46.18 \\
(46.16)\end{array}$ & $\begin{array}{c}2.92 \\
(2.98)\end{array}$ & $\begin{array}{c}8.26 \\
(8.28)\end{array}$ & $338.02\left[\mathrm{M}^{+}\right]$ \\
\hline
\end{tabular}


Table 4. The spectroscopic data of substituted mesalazine sulfonamides.

\begin{tabular}{|c|c|c|c|c|c|c|c|c|}
\hline \multirow[t]{3}{*}{ Entry } & \multirow[t]{3}{*}{$\mathrm{X}$} & \multicolumn{4}{|c|}{ Infrared bands $\left(v, \mathrm{~cm}^{-1}\right)$} & \multicolumn{3}{|c|}{ Chemical Shifts $(\delta, \mathrm{ppm})$} \\
\hline & & \multirow[t]{2}{*}{$\mathrm{N}-\mathrm{H}$} & \multirow[t]{2}{*}{$\mathrm{S}=\mathrm{O}_{\mathrm{as}}$} & \multirow[t]{2}{*}{$\mathrm{S}=\mathrm{O}_{\mathrm{s}}$} & \multirow[t]{2}{*}{$\mathrm{C}=\mathrm{O}$} & ${ }^{1} \mathrm{H}$ & \multicolumn{2}{|c|}{${ }^{13} \mathrm{C}$} \\
\hline & & & & & & $\mathrm{NH}$ & $\mathrm{COOH}$ & $\mathrm{C}-\mathrm{OH}$ \\
\hline 1 & $\mathrm{H}$ & 3262.4 & 1311.9 & 1158.0 & 1695.9 & 10.832 & 172.4 & 159.64 \\
\hline 2 & $4-\mathrm{Br}$ & 3263.2 & 1332.8 & 1156.0 & 1670.8 & 10.853 & 172.36 & 159.83 \\
\hline 3 & $4-\mathrm{Cl}$ & 3262.5 & 1333.8 & 1157.3 & 1670.8 & 10.077 & 171.06 & 158.71 \\
\hline 4 & $2-\mathrm{F}$ & 3264.4 & 1321.2 & 1168.7 & 1694.1 & 10.364 & 171.58 & 158.10 \\
\hline 5 & $4-\mathrm{F}$ & 3264.5 & 1325.7 & 1161.5 & 1670.8 & 10.290 & 171.53 & 159.15 \\
\hline 6 & $4-\mathrm{OCH}_{3}$ & 3250.1 & 1333.9 & 1158.0 & 1677.3 & 9.893 & 171.67 & 158.69 \\
\hline 7 & $4-\mathrm{CH}_{3}$ & 3262.8 & 1333.3 & 1157.3 & 1669.9 & 10.330 & 171.65 & 158.74 \\
\hline 8 & $2-\mathrm{NO}_{2}$ & 3293.2 & 1322.8 & 1175.9 & 1665.6 & 10.446 & 171.53 & 159.35 \\
\hline 9 & $4-\mathrm{NO}_{2}$ & 3263.6 & 1311.9 & 1159.5 & 1670.8 & 10.399 & 171.5 & 159.21 \\
\hline
\end{tabular}

The NH proton chemical shift obtained at 10.077 was not correlated with any of the ${ }^{13} \mathrm{C}$ chemical shifts. The ring proton chemical shifts are centered with the ring carbon chemical shifts. The solvent peak was correlated.

\subsection{Mass spectral study}

The mass spectrum and the splitting pattern of 5(4-chlorophenylsulfonamido)-2-hydroxybenzoic acid (entry 3, Table 3) are shown in Fig. 8.

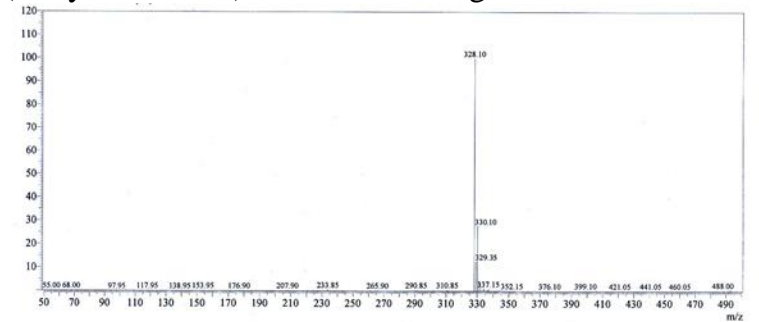

Figure 8. Mass spectrum of 5-(4chlorophenylsulfonamido)-2-hydroxybenzoic acid compound.

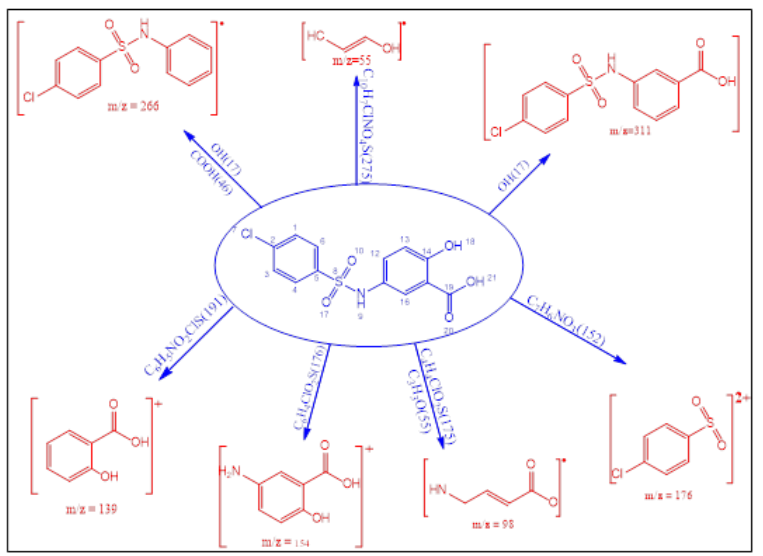

Figure 9. Mass splitting pattern of 5-(4chlorophenylsulfonamido)-2-hydroxybenzoic acid compound.

The mass of mesalazine sulfonamide derivative of 5-(4-chlorophenylsulfonamido)-2-hydroxybenzoic acid are $\mathbf{M}^{+2}$ because of the halogen substitution it shows 329.35. From the chemical impact spectrum, the splitting pattern of the 5-(4chlorophenylsulfonamido)-2-hydroxybenzoic acid is shown in Fig. 9.

Consequently, the experimental data confirmed the synthesis of substituted mesalazine sulfonamides. On the basis of their potential antibacterial activity, the obtained sulfonamide derivative may be used as drugs. Therefore, the study of substituted mesalazine sulfonamides properties looks promising in terms of a future work.

\section{Conclusions}

The copper/zeolite, obtained by a liquid phase deposit method in the reaction between a Y zeolite clay and copper nitrate, was successfully used as catalyst in the microwave-assisted synthesis of some novel sulfonamide derivatives.

This microwave assisted highly reusable $\mathrm{Cu}^{2+} /$ zeolite catalyzed sulfonamide synthesis protocol offers a simple, easier work-up procedure, no side reactions and high yield.

\section{References}

[1] G.W.V. Cave, C.L. Raston and J.L. Scott, Chem. Commun. 21, 2159 (2001).

[2] D. Azarifar and F. Soleimaneia, RSC Adv. 4, 12119 (2014).

[3] S. V. Chankeshwara and A. K. Chakraborti, J. Mol. Catal. A: Chem. 253, 198 (2006).

[4] D. Habibi and O. Marvi, Catal. Commun. 8, 127 (2007).

[5] K. Shimizu, T. Higuchi, E. Takasugi, T. Hatamachi, T. Kodama and A. Satsuma, J. Mol. Catal. A: Chem. 284, 89 (2008).

[6] F. Tamaddon, A. Nasiri and S. Farokhi, Catalysis Communications. 12, 1477 (2011).

[7] A.R. Massah, S. Sayad and S. Ebrahimi, RSC Adv. 2, 6606 (2012).

[8] B.S. Anandakumar, M.B. Madhusudana Reddy, K.V. Thipperudraiah, G.T. Chandrappa and M.A. Pasha, Chemical Papers. 67, 135 (2013). 
[9] W. Kruis, S. Schreiber, D. Theuer, J.W. Brandes, E. Schütz, S. Howaldt, B. Krakamp, J. Hämling, H. Mönnikes, I. Koop, M. Stolte, D. Pallant and U. Ewald, Gut. 49, 783 (2001).

[10] C. Barbey, R. Bouasla, M. Berredjem, N. Dupont, P. Retailleau, N.E. Aouf and M. Lecouvey, Tetrahedron 68, 9125 (2012).
[11] Y. F. Chen, P. Rabu, G. Pourroy and S. Vilminot, Eur. J. Solid State Inorg. Chem. 32, 1065 (1995).

Received: 17 March 2016

Received in revised form: 28 April 2016

Accepted: 06 May 2016 